\title{
Peptide-based Synthetic Design, Construction and Morphology of Soft Structures
}

\author{
Sudipta Mondala , Apurba K. Barmanª, and Sandeep Verma ${ }^{\star a b}$
}

\begin{abstract}
Peptide-based self-assembly offers a unique entry into the construction of soft structures with interesting material properties and functions. Aromatic amino acid-containing peptides are commonly employed as they exhibit high propensity to aggregate due to increased hydrophobic content, promotion of favorable secondary structures, planarity and the possibility of $\pi-\pi$ interactions. Incorporation of covalent scaffolds, stimuli-responsive handles and carbohydrate moieties augment beneficial characteristics to the resulting peptide conjugates. These modifications were shown to enforce self-association, elicit stimuli response and achieve improved hydrophilic properties, to name but a few.
\end{abstract}

Keywords: Carbohydrates · Fibers · Peptide conjugates · Scaffolds · Self-assembly $\cdot$ Vesicles

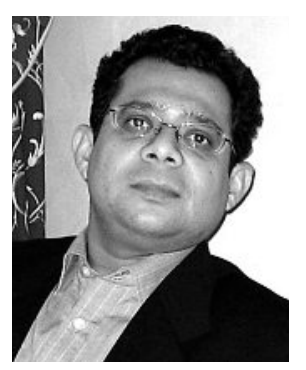

Sandeep Verma was born in Kanpur, India, and completed his education at Banaras Hindu University, Varanasi. Subsequent

his Ph.D. from University Illinois Medical Center, Chicago (1994), he did postdoctoral stints at Johns Hopkins Medical Institutions, Baltimore, USA, and at the Max-Planck-Institut für experimentelle Medizin, Göttingen, Germany. He joined Department of Chemistry, Indian Institute of Technology Kanpur, in 1997, where he currently holds positions of Professor and Shri Deva Raj Endowed Chair. He is also affiliated to the DST Thematic Unit of Excellence on Soft Nanofabrication and Center for Environment Science and Engineering, at IIT Kanpur. Amongst many distinctions, he has received the DAE-SRC Outstanding Investigator Award (2012), Shanti Swarup Bhatnagar Prize (2010), CDRI Award for Excellence in Drug Research (2009), Swarnajayanti

\footnotetext{
${ }^{*}$ Correspondence: Prof. S. Verma ${ }^{a b}$ aDepartment of Chemistry

'DST Thematic Unit of Excellence on Soft

Nanofabrication

Indian Institute of Technology Kanpur

Kanpur - 208016 (UP) India

Tel.: +91512 2597643

Fax: +91512 2597436

E-mail: sverma@iitk.ac.in
}

Fellowship (2005), B M Birla Science Prize (2004). He is an elected Fellow of Indian Academy of Sciences and National Academy of Sciences, India, and also a Senior Fellow, Zukunftskolleg, University of Konstanz, Germany. He serves on the editorial boards of Chemical Communications, Chemistry \& Biology and Journal of Chemical Sciences. His research interests include metal-nucleobase interactions, peptide/protein self-assembly, and soft matter.

\section{Introduction}

The process of autonomous self-assembly perhaps came into effect during prebiotic evolution when primordial macromolecular templates were assembled on natural surfaces and the formation of protocell, from simpler constituents, was inextricably linked to the emergence of life and evolution. Self-assembly is defined as a molecular process where smaller, simple entities self-associate, through a number of non-covalent interactions, to afford complex hierarchical architectures. Abundant examples of this intriguing phenomenon are encountered in natural systems, which include the assembly of actin filaments, microtubule polymerization and formation of viral capsids, to name just a few. ${ }^{[1]}$ Gaining inspiration from naturally assembled systems, various biomimetic approaches have been described in contemporary literature. ${ }^{[2]}$

In particular, peptides and proteins offer interesting starting points for triggering this phenomenon owing to the chemical diversity of side-chains, ease of chemical modifications and the possibility of ex- ploiting a host of non-covalent and metalassisted interactions, to stabilize higher order ensembles. ${ }^{[3]}$ Consequently, a variety of nanoscale morphologies such as fibers, vesicles, nanotubes are observed for amino acids and short peptides and these biocompatible soft materials have been used for diverse biological, medical and material applications. ${ }^{[4]}$

However, precise control over shape and size selectivity in peptide-based nanostructures requires deeper insight into operating mechanisms associated with the self-assembly process. In this review, we endeavor to describe our efforts to discover and apply strategies for peptide conjugate design, study of their solution-phase selforganization and possible applications.

\section{Design Strategies}

Our designs substantially rely on the choice of aromatic amino acid-containing short peptides, flexible or rigid scaffolds for conjugation and carbohydrate modifications. The latter modification is usually invoked to impart and improve water solubility, a feature important for cell and biological applications. These strategies are discussed in the following sections.

\subsection{Aromatic Peptides}

The presence of aromatic amino acids in peptides is considered important as it promotes favorable $\pi$-stacking and hydrophobic interactions. ${ }^{5]}$ Remarkably, this non-bonding feature has a significant role in secondary structure stabilization as 61\% Phe residues, 59\% Trp residues and $54 \%$ Tyr residues are involved in proteinprotein hotspot interfacial interactions. 
Their role is important for self-assembly as their aromatic nature augments necessary thermodynamic considerations and engineers definite packing patterns to confer directionality and orientation in these ensembles. ${ }^{[5,6]}$

The presence of aromatic amino acids in peptide sequences leads to an enhanced propensity to aggregate due to increased hydrophobic content, promotion of favorable secondary structures, planar geometry and to an extent, the possibility of $\pi-\pi$ interactions. ${ }^{[6 b, 7]}$ However, these observations are mostly amino acid and sequencedependent. Starting from self-assembly of phenylalanine to reveal amyloidogenic fibers, ${ }^{[8]}$ to accelerated self-assembly and hydrogelation exhibited by Fmocprotected pentafluorophenylalanine, ${ }^{[9]}$ to self-assembling dipeptide nanotubes, ${ }^{[10]}$ the examples are far too many to enlist completely in this review.

Tryptophan is one of the most conserved aromatic amino acids in protein sequences. Indole, the heterocyclic ring present in tryptophan, self-assembles when alkylated at the $\mathrm{N}(1)$ or $\mathrm{N}(3)$ position to give vesicular structures in aqueous solution. ${ }^{[11]}$ Stability of alkylated indole/ tryptophan could be ascribed not only to its hydrophobicity, but also to electrostatic and dispersion forces. ${ }^{[12]}$ In another study, aggregates of tryptophan-containing heptapeptide exhibited the property of chloride ion transport from liposomes, in bilayer conductance studies. ${ }^{[13]}$ Being aware of beneficial non-bonding interactions due to aromatic rings, we have extensively employed tryptophan-containing peptides around flexible or rigid scaffolds to create supramolecular ensembles in solution.

\subsection{Covalent Scaffolds}

Conjugation of short peptide sequences to covalent scaffolds is a useful strategy to mimic hierarchical organization present in proteins. This approach provides favorable thermodynamic considerations by curtailing chain dynamics, thereby inducing self-aggregation and structure formation. This approach was successfully applied for the stabilization of collagen triple helix mimics around the $C_{3}$-symmetric TREN scaffold, while introduction of additional responsive sites in such scaffolded structures have resulted in the formation of fibers, gels, spheres, and meshes, with potential applications in drug delivery, tissue engineering, and regenerative medicine. ${ }^{[14]}$ Some other scaffolds for covalent conjugation described in literature include cis-1,3,5-trimethylcyclohexane-1,3,5tricaboxylic acid,[15] tris(2-aminoethyl) amine)-(suc-OH $)_{3}{ }^{[14 a]}$ and $\beta$-Ala-Tris, ${ }^{[16]}$ to name just a few. Some early reports have also described lysine dimers, 6-aminohexanoic acid and 1,2,3-propanetricarboxylic acid, ${ }^{[17]}$ as covalent scaffolds. We have used this strategy to induce self-assembly in non-aggregating short peptide sequences. Some of the representative scaffolds employed by us for self-assembly studies are described below.

\subsubsection{Linear Flexible Linkers}

In one study with GPG palindromic tripeptide, we conducted molecular dynamics (MD) simulations to investigate its propensity to aggregate in solution, as it displayed nicely layered crystallographic signature in the solid state. ${ }^{[18]}$ In the first simulation, four randomly oriented GPG

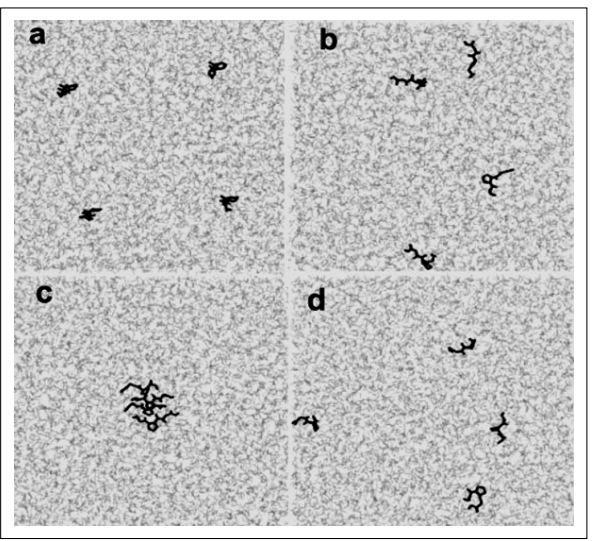

Fig. 1. MD simulations studies: (a) four randomly placed GPG tripeptide units; (b) snapshot of (a) after $10 \mathrm{~ns}$; (c) artificially stacked tripeptides; (d) snapshot of (c) after 2.5 ns. Reproduced by permission of The Royal Society of Chemistry from ref. [18]. peptides, placed in a box with methanol molecules, failed to aggregate in $15 \mathrm{~ns}$ (Fig. 1). None of the four GPG peptides achieved proximity to each other during the course of simulations suggesting a lack of intermolecular interactions favouring aggregation. In a second simulation, four GPG tripeptides were artificially stacked one over the other, but they quickly dissociated indicating their inability to retain the self-assembled structure (Fig. 1). These observations were also proven by microscopy studies. However, it was possible to enforce aggregation by conjugating two such palindromic tripeptides with a 1,2-diaminoethane linker. ${ }^{[18]}$ Formation of fibers in a time-dependent fashion was confirmed with atomic force microscopy and it was also possible to observe birefringence, after staining with Congo red dye, under a polarizing optical microscope (Fig. 2).

A linear linking scaffold was applied to conjugate a truncated pentapeptide from the copper-binding octarepeat domain (PHGGGWGQ) of the prion protein. ${ }^{[19]}$ As the latter is implicated in several neurodegenerative disorders, there is considerable interest to use peptide segments from such proteins to mimic and study the process of protein self-aggregation. We started working with the truncated pentapeptide PHGGG from the octarepeat domain, and interestingly, pentapeptide alone failed to exhibit aggregation as confirmed by microscopy analysis.[20] But, extensive fibrillation was observed when two such pentapeptides were conjugated to each other, from their C-terminus, with a linear 1,4-diaminobutane linker (Fig. 3).

The ability of PHGGG pentapeptide to aggregate was remarkably augmented when conjugated to 6-aminocaproic acid (3). Time-dependent growth of peptide fibrils from spherule-like pre-fibrillar structures was observed and the continuous growth process of fiber formation was recorded over a period of 15 days, with the help of optical microscopy (Fig. 4).[21] This study provided a crucial insight into the emergence of amorphous pre-fibrillar intermediates en route to the formation of full length peptide fibers.

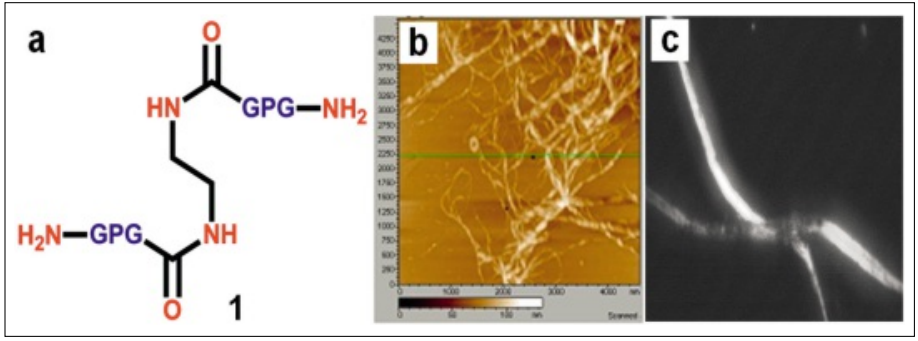

Fig. 2. (a) Structure of GPG conjugate 1; (b) AFM image of fibrillar networks of 1; (c) Optical microscopic image of fibers with Congo red staining. Reproduced by permission of The Royal Society of Chemistry from ref. [18].

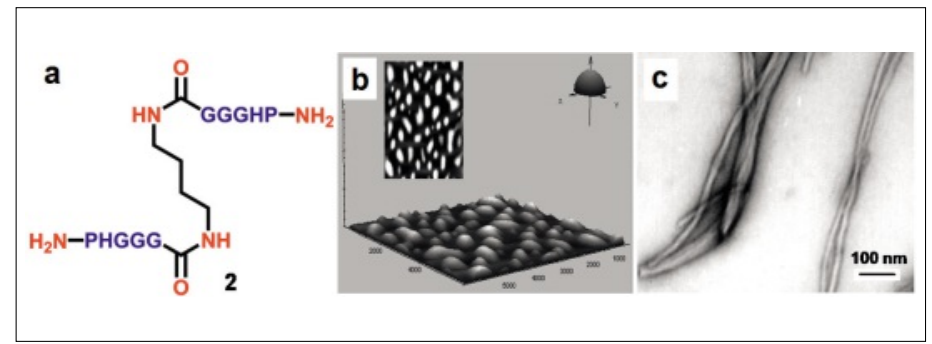

Fig. 3. (a) Structure of PHGGG bis-pentapeptide; (b) AFM image of freshly prepared solution of 2; (c) TEM image of seven days aged solution of 2. Reproduced by permission of The Royal Society of Chemistry from ref. [20]. 
Aggregation of full-length protein is often unmanageable for screening inhibitors given their insolubility in aqueous medium. Thus, it was interesting to note that $\mathbf{3}$ could serve as a suitable model system to screen inhibitory potential of microtubule poison colchicine and other small molecules for chemical intervention of peptide aggregation (Fig. 4). Incubation of $\mathbf{3}$ with colchicine at $\mathrm{t}=0$ or $\mathrm{t}=10$ days either led to the arrest of aggregation at spherical prefibrillar stage or it completely dissolved mature fibers, respectively.

\subsubsection{Rigid Aromatic Linker}

We also resorted to using 2,6-pyridinedicarboxylic acid as a rigid linker to influence peptide self-assembly. It could be envisaged that this rigid scaffold may aid supramolecular organization by restricting conformational entropy. ${ }^{[22]}$ To test this hypothesis, we conjugated two Trp-Trp dipeptides to 2,6-pyridinedicarboxylic acid to maximize aromatic $\pi-\pi$ interactions. Conjugate 4 afforded formation of spherical structures in solution. ${ }^{[23]}$ It is important to emphasize that dipeptide alone did not give stable structures in solution despite long incubation periods. Interestingly, 4 also exhibited selective interaction toward $\mathrm{Hg}^{2+}$ ions as determined by competitive titration experiments conducted with various metal ions. A detection limit of 200 $\mathrm{nM}$ was achieved for $\mathrm{Hg}^{2+}$ ions in a fluorescence-based assay. Curiously, binding of $\mathrm{Hg}^{2+}$ to soft spherical structures led to vesicle fusion, attributed to metal ion-assisted stacking of individual vesicles with each other (Fig. 5).

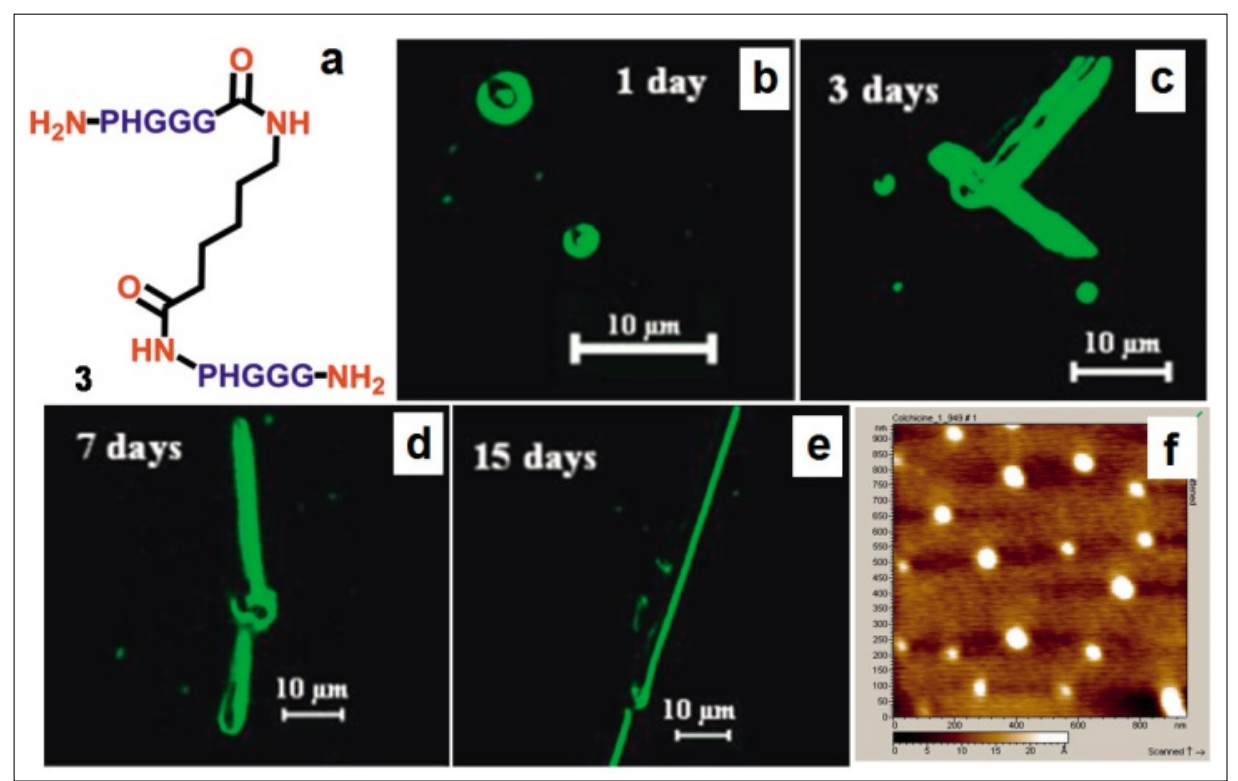

Fig. 4. (a) Structure of PHGGG bis-conjugate with 6-aminocaproic acid (3). Snap-shots of timedependent growth of 3: (b) spherical pre-fibrillar formation at day 1; (c) fibrous growth from spherical nuclei (day 3); (d) elongation of fibrils (day 7); (e) formation of fully extended fibrils (day 15). (f) AFM micrograph of $\mathbf{3}$ after co-incubation with colchicines. Reprinted with permission from ref. [21]; Copyright (2007) American Chemical Society.

Stable interaction of $\mathbf{4}$ with $\mathrm{Hg}^{2+}$ ions, as determined from fluorescence and selfassembly studies, motivated us to further study this conjugate for mercury ion extraction from living cells. E. Coli $\mathrm{DH} 5 \alpha$ cells were exposed to $\mathrm{Hg}^{2+}$ ions at a concentration completely inhibitory towards bacterial growth, followed by the addition of 4 to the culture media. Cells loaded with mercury ions, when challenged with $\mathbf{4}$, resulted in a dramatic rescue against mercury toxicity, in a concentration-dependent fashion (Fig. 5). ${ }^{[23]}$ Thus, it is possible to design soft structures with suitable metal ion-responsive linkers for biological applications.

\subsection{3 $C_{3}$-symmetric Flexible Linker}

Tris(2-aminoethyl)amine (TREN) is a symmetric scaffold where nodal tertiary nitrogen and three primary amino groups provide a useful flexible, symmetric geometry to mount peptide sequences. Clathrin, a protein crucial for cellular transport and

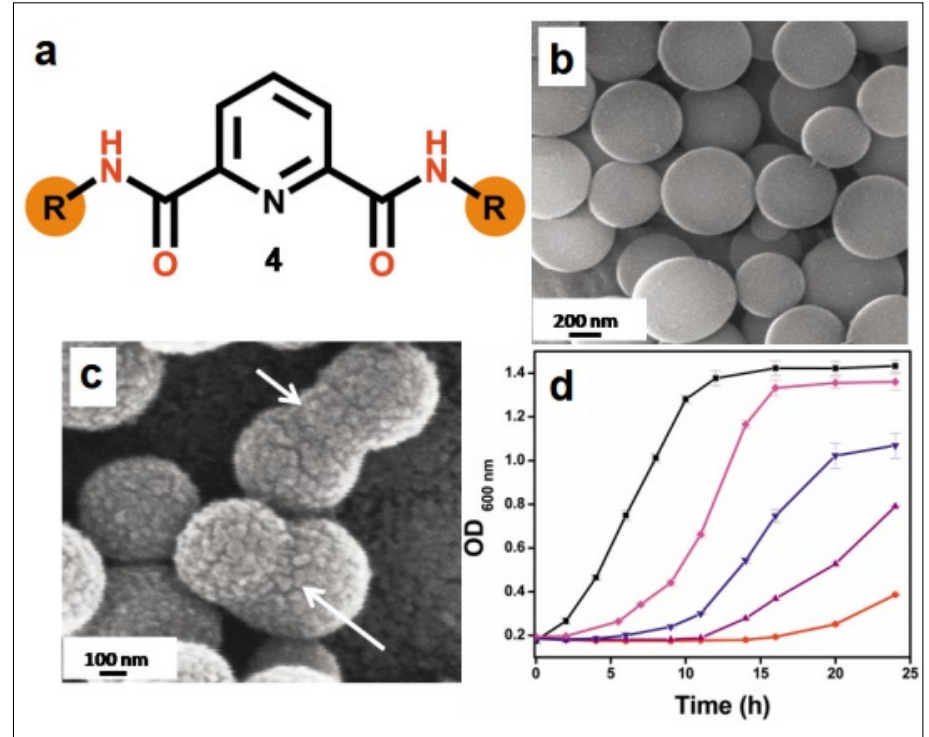

Fig. 5. (a) Structure of pyridine-ditryptophan conjugate $(R=\operatorname{Trp}$-Trp); (b) Vesicular morphology of compound 4; (c) SEM micrograph of $\mathbf{4}$ in the presence of mercury ions; (white arrow represents vesicle fusion); (d) Rescue of $E$. coli DH5 $\alpha$ cells from mercury toxicity. (black) Normal growth; cells pre-treated with $1.8 \mu \mathrm{M} \mathrm{Hg}^{2+}$ followed by addition of (pink) $40 \mu \mathrm{M}$, (blue) $20 \mu \mathrm{M}$ and (maroon) $10 \mu \mathrm{M}$ of 4 ; (red) cells treated with $1.8 \mu \mathrm{M} \mathrm{Hg}^{2+}$. Reprinted from ref. [23] with permission from Elsevier.

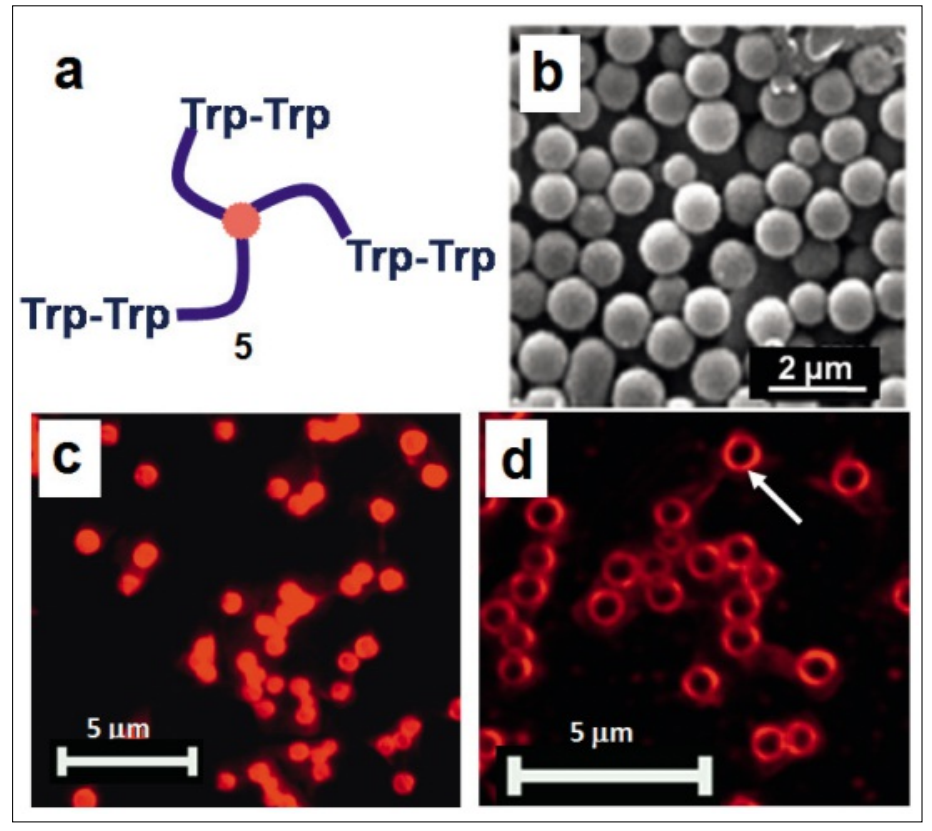

Fig. 6. (a) Triskelion ditryptophan conjugate 5; (b) SEM image of the selfassembled structures of 5; (c) Encapsulation of dye in the vesicles of triskelion conjugate; (d) Release of encapsulated dye upon mild acidification. Reproduced with permission from ref. [25], Copyright @2007 WileyVCH Verlag GmbH \& Co. KGaA, Weinheim. 

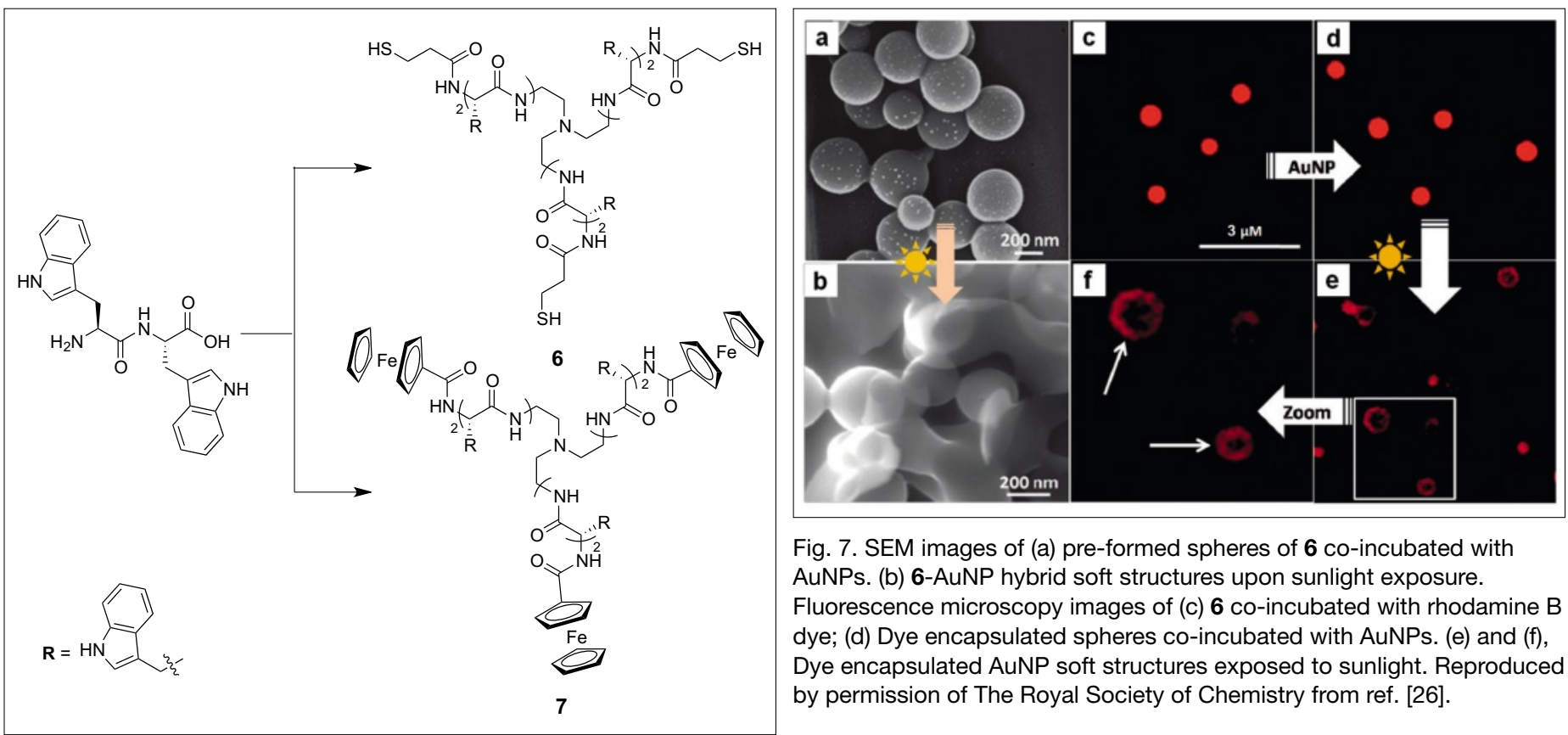

Fig. 7. SEM images of (a) pre-formed spheres of 6 co-incubated with AuNPs. (b) 6-AuNP hybrid soft structures upon sunlight exposure.

Fluorescence microscopy images of (c) 6 co-incubated with rhodamine $B$ dye; (d) Dye encapsulated spheres co-incubated with AuNPs. (e) and (f), Dye encapsulated AuNP soft structures exposed to sunlight. Reproduced by permission of The Royal Society of Chemistry from ref. [26].

Scheme 1. Molecular structures of different conjugates based on Trp-Trp dipeptide and TREN.

small molecule trafficking, is a striking example of natural self-assembling system employing $C_{3}$-symmetric triskelion structure implicated for the formation of cagelike architectures. ${ }^{[24]}$ We envisioned that aromatic dipeptide conjugation to TREN would afford a bioinspired synthetic triskelion construct suitably poised for self-assembly studies.

The MM+-optimized structure of TrpTrp-TREN conjugate (5) exhibited an overlap of two indole rings, suggesting a critical role of $\pi$-stacking in ensuing organization of synthetic triskelions. ${ }^{[25]}$ Rapid assembly to reveal spherical structures occurred as soon as synthetic triskelion was dissolved in aqueous methanol, followed by microscopy studies (Fig. 6). It was proposed that interdigitation of indole residues in Trp-Trp arms leads to formation of nanocage-like structures in bioinspired construct for dye encapsulation. Interestingly, mild acidification made the vesicular structures leaky, resulting in the release of the encapsulated fluorescent dye (Fig. 6). ${ }^{[25]}$ Extreme acidification completely disrupted spherical morphology, which could be reversed on neutralization of solution, thus offering entry into $\mathrm{pH}$ responsive soft cages for encapsulation and transport.

As an interesting variation to the design of synthetic triskelion, thiol moieties were incorporated in the core structure of 5 to get a thiolated triskelion conjugate $\mathbf{6}$ (Scheme 1). Introduction of a thiol group was considered to also explore the interaction of gold nanoparticles (AuNP) with self-assembled soft structures. ${ }^{[26]}$ Spherical
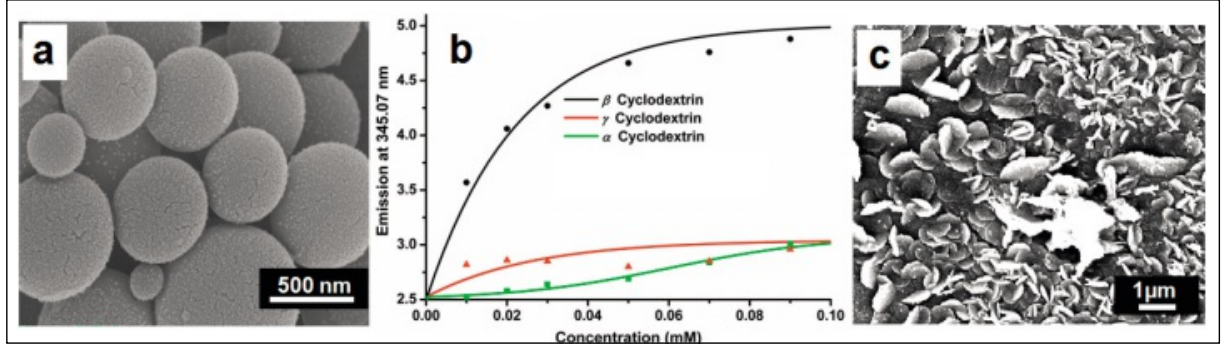

Fig. 8. (a) Self-assembled soft structures of compound 7; (b) Fluorescence enhancement of $\mathbf{7}$ in presence of different cyclodextrins; (c) Morphological behaviour of the soft structures in presence of cyclodextrin. Reprinted from ref. [27] with permission from Elsevier.

morphology was observed, which coalesced to form fused structures upon aging. As this process could be reversed by treatment with dithiothreitol reduction, it was proposed that surface-exposed thiol groups undergo aerial oxidation to afford fused structures through disulfide crosslink formation.

This information was exploited to arrive at AuNP decorated spherical structures, which responded to the stimuli of electromagnetic plasmonic heating when exposed to sunlight. The soft peptide scaffold underwent deformation due to generation of thermal energy, which prompted us to study dye encapsulation and release through sunlight exposure (Fig. 7). [26]

Yet another modification was achieved by conjugating electroactive ferrocene moiety to arrive at ferrocenylated triskelion conjugate 7 (Scheme 1), in order to investigate electrochemical properties of self-assembled structures. [27] Analogous to other TREN-based conjugates, 7 also selfassembled to reveal spherical structures through the fusion of spherical subunits of smaller dimensions (Fig. 8). Notably, tryptophan fluorescence was quenched in self-assembled structure possibly due to resonance energy transfer from Trp to a proximal ferrocene moiety. Fluorescence could be restored by forming stable hostguest complex between ferrocene moieties and exogenously added $\alpha-, \beta$-, or $\gamma$-cyclodextrins (Fig. 8), ${ }^{[27]}$ to release Trp side chains for excitation/emission process. This process, however, also led to a change in morphology to flattened disclike structures.

\subsection{Carbohydrate Conjugation}

Incorporation of carbohydrate moieties in synthetic molecules imparts hydrophilic character, confers multivalency and offers specific interactions with several receptor proteins in a number of tissue-types. ${ }^{[28]}$ In addition, the hydrophilic property of carbohydrates is of special interest to generate amphiphilic nanostructures of various shapes and multivalency properties. ${ }^{[29]} \mathrm{A}$ novel approach of creating self-assembled structures from carbohydrate amphiphiles, derived from bio-based feedstock, promises to open up limitless possibilities of new molecules to create materials with focused applications. [30] 


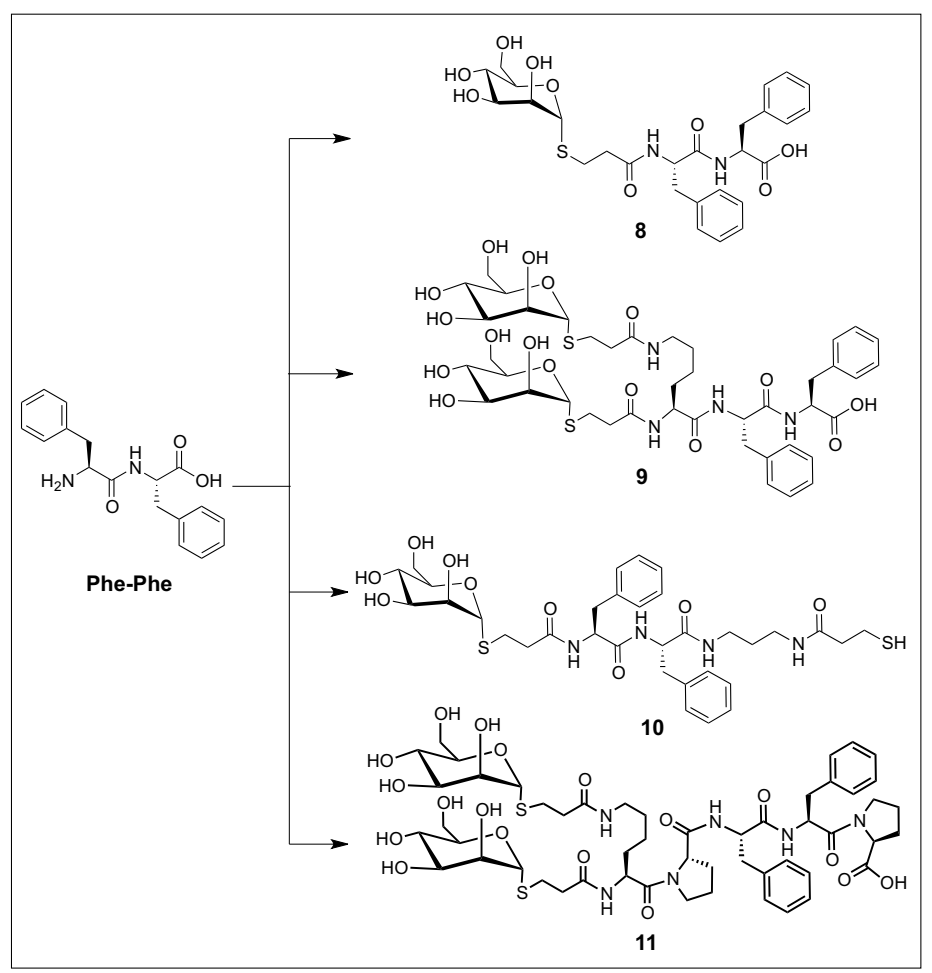

Scheme 2. Molecular structures of different constructs after conjugation with mannose residues to Phe-Phe dipeptide.

Phe-Phe, a well-known aromatic dipeptide, yields robust nanotubes. ${ }^{[10]}$ In order to improve its aqueous solubility, mannose residues were covalently attached to yield constructs 8-10 (Scheme 2). ${ }^{[31]}$ Interestingly, mannose conjugation leads to a morphology switch from tubular to fibrillar and spherical structures.

While single mannose conjugate $\mathbf{8}$ afforded fibrillar morphology, conjugation of two mannose units in $\mathbf{9}$, attached via a lysine residue at the $\mathrm{N}$-terminus of dipeptide, resulted in the formation of spherical self-assembled structures (Fig. 9). Introduction of a thiol group in monomannose conjugate $\mathbf{8}$ afforded 10, which switched the morphology from fibrillar to spherical (Fig. 9).

Mannose residues were also conjugated to a hydrophobic tetrapeptide PFFP, known to result in the formation of spherical structures, ${ }^{[32]}$ through $\alpha$ - and $\varepsilon$-amino groups of lysine residue (11) (Scheme 2). ${ }^{[33]}$ Aqueous solubility was considerably enhanced upon mannose conjugation and construct 11 self-organized to give spherical structures resembling to those of PFFP (Fig. 9). Results of the turbidimetric assay with lectin Concanavalin A suggested that hydrophilic mannose moieties decorated outer surface exposed to the aqueous environment. These structures were able to encapsulate pBR322 plasmid DNA inside the hollow cavity following mild ultrasonication, as confirmed by electrophoresis and acridine orange binding experiments (Fig. 9). Such studies suggest that hydrophilic peptide-based spherical structures could serve as containers for macromolecular guests and possibly extended for cell transfection. ${ }^{[33]}$

\section{Conclusions}

Peptide-based soft structures were constructed from aromatic amino acidcontaining peptides by employing covalent conjugation to flexible or rigid scaffolds and by conjugation to hydrophilic carbohydrate residues. A variety of morphologies were possible through molecular design and many constructs were used for dye encapsulation, macromolecular containment and stimuli-responsive release of guest molecules. In one example, soft structures were also used to rescue bacteria from mercury poisoning, thereby suggesting wide ranging applications when coupled with suitable design strategies. Newer studies in soft matter research would continue to provide impetus for creation of new materials for various applications.

\section{Acknowledgments}

All past and present lab members are thanked for their active participation in peptide-based soft matter research. We would like to thank Department of Science and Technology for continued financial support and to DST Thematic Unit of Excellence on Soft Nanofabrication for microscopy facility.

Received: October 20, 2012
[1] (a) E. Nogales, K. H. Downing, Curr. Opin Cell Biol. 1998, 10, 16; (b) R. H. Wade, Mol. Biotechnol. 2009, 43, 177; (c) T. Oda, M. Iwasa, T. Aihara, Y. Maeda, A. Narita, Nature 2009, 457, 441; (d) R. Dominguez, K. C. Holmes, Ann. Rev. Biophys. 2011, 40, 169; (e) A. Zlotnick, S. Mukhopadyay, Trends Microbiol. 2011, 19, 14; (f) D. G. Angelescu, P. Linse, Soft Matter 2008, 4, 1981.

[2] (a) A. Kuzyk, R. Schreiber, Z. Fan, G. Pardatscher, E-M. Roller, A. Högele, F. C. Simmel, A. O. Govorov, T. Liedl, Nature 2012, 483, 311; (b) A. M. Kushner, Z. Guan, Angew. Chem. Int. Ed. 2011, 50, 9026; (c) D. Ackermann, S. S. Jester, M. Famulok, Angew. Chem. Int. Ed. 2012, 51, 6771; (d) L. Ziserman, H-Y. Lee, S. R. Raghavan, A. Mor, D. Danino, J. Am. Chem. Soc. 2011, 133, 2511; (e) A. R. Hirst, S. Roy, M. Arora, A. K. Das, N. Hodson, P. Murray, S. Marshall, N. Javid, J. Sefcik, J. Boekhoven, J. H. van Esch, S. Santabarbara, N. T. Hunt, R. V. Ulijn, Nat. Chem. 2010, 2, 1089.

[3] (a) M. A. Case, G. L. Mclendon. Acc. Chem Res. 2004, 37, 754; (b) P. Arosio, M. Owczarz, H. Wu, A. Butté, M. Morbidelli, Biophys. J. 2012, 102, 1617; (c) D. Yu, M. Deng, C. He, Y. Fan, Y. Wang, Soft Matter 2011, 7, 10773; (d) V. Castelletto, I. W. Hamley, J. Adamcik, R. Mezzenga, J. Gummel, Soft Matter 2012, 8, 217; (e) C. J. Bowerman, W. Liyanage, A. J. Federation, B. L. Nilsson, Biomacromolecules 2011, 12, 2735; (f) Q. Meng, Y. Kou, X. Ma, Y. Liang, L. Guo, C. Ni, K. Liu, Langmuir 2012, 28, 5017; (g) S-Y. Qin, S-S. Xu, R-X. Zhuo, X-Z. Zhang, Langmuir, 2012, 28, 2083; (h) C. Subbalakshmi, S. V. Manoramab, R. Nagaraja, J. Pept. Sci. 2012, 18, 283.

[4] (a) A. C. A. Wan, J. Y. Ying, Adv. Drug Delivery Rev. 2010, 62, 731; (b) J. B. Matsona, S. I. Stupp, Chem. Commun. 2011, 47, 7962; (c) X. Zhaoab, S. Zhang, Chem. Soc. Rev. 2006, 35, 1105; (d) Y. Song, S. R. Challa, C. J. Medforth, Y. Qiu, R. K. Watt, D. Peña, J. E. Miller, F. van Swol, J. A. Shelnutt, Chem. Commun. 2004, 1044.

[5] (a) S. K. Burley, G. A. Petsko, Science $\mathbf{1 9 8 5}$, 229, 23; (b) J. S. Nowick, Acc. Chem. Res. 2008, 41, 1319; (c) E. A. Meyer, R. K. Castellano, F. Diederich, Angew. Chem. Int. Ed. 2003, 42, 1210; (d) M. L. Waters, Curr. Opin. Chem. Biol. 2002, 6, 736 .

[6] (a) I. S. Moreira, J. M. Martins, R. M. Ramos, P. A. Fernandes, M. J. Ramos, Biochim. Biophys. Acta, 2012, http://dx.doi.org/10.1016/j. 
bbapap.2012.07.005; (b) E. Gazit, FASEB J. 2002, 16, 77; (c) P. Chakrabarti, R Bhattacharyya, Progr. Biophys. Mol. Biol. 2007, 95, 83; (d) L. M. Salonen, M. Ellermann, F. Diederich, Angew. Chem. Int. Ed. 2011, 50, 4808.

[7] (a) T. M. Doran, A. J. Kamens, N. K. Byrnes, B. L. Nilsson, Proteins 2012, 80, 1053; (b) G. G. Tartaglia, A. Cavalli, R. Pellarin, A. Caflisch, Protein Sci. 2004, 13, 1939; (c) F. Bemporad, G. Calloni, S. Campioni, G. Plakoutsi, N. Taddei, F. Chiti, Acc. Chem. Res. 2006, 39, 620; (d) C. Tang, R.V. Ulijn, A. Saiani, Langmuir 2011, 27, 14438.

[8] L. Adler-Abramovich, L. Vaks, O. Carny, D. Trudler, A. Magno, A. Caflisch, D. Frenkel, E. Gazit, Nat. Chem. Biol. 2012, 8, 701.

[9] D. M. Ryan, S. B. Anderson, F. T. Senguen, R. E. Youngman, B. L. Nilsson, Soft Matter 2010, 6,475 .

[10] (a) M. Reches, E. Gazit, Science, 2003, 300, 625; (b) M. Reches, E. Gazit, Nat. Nanotechnol. 2006, $1,195$.

[11] (a) E. Abel, M. F. Fedders, G. W. Gokel, J. Am. Chem. Soc. 1995, 117, 1265; (b) E. Abel, S. L. De Wall, W. B. Edwards, S. Lalitha, D. F. Covey, G. W. Gokel, J. Org. Chem. 2000, 65, 5901.

[12] M. Mons, I. Dimicoli, B. Tardivel, F. Piuzzi, V. Brenner, P. Millié, J. Phys. Chem. A 1999, 103, 9958.

[13] M. M. Daschbach, S. Negin, L. You, M. Walsh, G. W. Gokel, Chem. Eur. J. 2012, 18, 7608.
[14] (a) J. Kwak, A. De Capua, E. Locardi, M. Goodman, J. Am. Chem. Soc. 2002, 124, 14085; (b) Y. Li, X. Mo, D. Kim, S. M. Yu, Biopolymers 2011, 95, 94; (c) D. E. Przybyla, J. Chmielewski, Biochemistry 2010, 49, 4411.

[15] (a) Y. Feng, G. Melacini, J. P. Taulane, M. Goodman, J. Am. Chem. Soc. 1996, 118, 10351 (b) G. Melacini, Y. Feng, M. Goodman, J. Am. Chem. Soc. 1996, 118, 10359; (c) M. Goodman, Y. Feng, G. Melacini, J. P. Taulane, J. Am Chem. Soc. 1996, 118, 5156.

[16] (a) G. A. Kinberger, W. Cai, M. Goodman, J. Am. Chem. Soc. 2002, 124, 15162; (b) W. Cai, D. Wong, G. A. Kinberger, S. W. Kwok, J. P. Taulane, M. Goodman, Bioorg. Chem. 2007, 35, 327.

[17] (a) C. G. Fields, B. Grab, J. L. Lauer, G. B. Fields, Anal. Biochem. 1995, 231, 57; (b) W. Roth, E. Heidemann, Biopolymers 1980, 19 1909; (c) S. Thakur, D. Vadolas, H-P. Germann, E. Heidemann, Biopolymers 1986, 25, 1081; (d) B. Grab, A. J. Miles, L. T. Furcht, G. B. Fields, J. Biol. Chem. 1996, 271, 12234.

[18] K. K. Prasad, C. S. Purohit, A. Jain, R. Sankararamakrishnan, S. Verma, Chem. Commun. 2005, 2564.

[19] (a) D. L. Mendola, A. Pietropaolo, G. Pappalardo, C. Zannoni, E. Rizzarelli, Curr Alzheimer. Res. 2008, 5, 579; (b) L. Hong, J. D. Simon, Metallomics 2011, 3, 262; (c) G. L. Millhauser, Annu. Rev. Phys. Chem. 2007, 58 , 299.
[20] C. Madhavaiah, S. Verma, Chem. Commun. 2004, 638.

[21] S. Ghosh, S. Verma, J. Phys. Chem. B 2007, 111,3750 .

[22] S. Maity, P. Jana, S. K. Maity, D. Haldar, Langmuir 2011, 27, 3835.

[23] S. Mondal, S. Swaroop, R. Gurunath, S. Verma, Tetrahedron Lett. 2010, 51, 6111.

[24] A. Fotin, Y. Cheng, P. Sliz, N. Grigorieff, S. C. Harrison, T. Kirchhausen, T. Walz, Nature, 2004, 432, 573.

[25] S. Ghosh, M. Reches, E. Gazit, S. Verma, Angew. Chem. Int. Ed. 2007, 46, 2002.

[26] A. K. Barman, S. Verma, Chem. Commun. 2010, 46, 6992.

[27] S. Mondal, S. Ghosh, S. Verma, Tetrahedron Lett. 2010, 51, 856

[28] (a) J-H. Ryu, E. Lee, Y-B. Lim, M. Lee, J. Am. Chem. Soc. 2007, 129, 4808; (b) J. J. Lundquist, E. J. Toone, Chem. Rev. 2002, 102, 555.

[29] Y-b. Lim, M. Lee, Org. Biomol. Chem. 2007, 5, 401.

[30] P. K. Vemula, G. John, Acc. Chem. Res. 2008, $41,769$.

[31] N. Gour, A. K. Barman, S. Verma, J. Pept. Sci. 2012, 18, 405 .

[32] K. B. Joshi, S. Verma, J. Pept. Sci. 2008, 14, 11863.

[33] (a) N. Gour, S. Mondal, S. Verma, J. Pept. Sci. 2011, 17, 148; (b) N. Gour, C. S. Purohit, S. Verma, R. Puri, S. Ganesh, Biochem. Biophys. Res. Commun. 2009, 378, 503. 